\title{
AMPK-Mediated Regulation of Lipid Metabolism by Phosphorylation
}

\author{
Qi Wang, ${ }^{a, \#}$ Shudong Liu, ${ }^{b, \#}$ Aihua Zhai, ${ }^{a}$ Bai Zhang, ${ }^{a}$ and Guizhen Tian*,a \\ ${ }^{a}$ Department of Pharmacy, The Fifth People's Hospital of Jinan; Jinan, Shandong 250022, P. R. \\ China: and ${ }^{b}$ Department of Endocrinology, Shandong Rongjun General Hospital; \\ Jinan, Shandong 250013, P. R. China. \\ Received September 5, 2017; accepted April 12, 2018; \\ advance publication released online April 28, 2018
}

\begin{abstract}
AMP-activated protein kinase (AMPK) is a metabolic sensor in mammals that is activated when ATP levels in the cell decrease. AMPK is a heterotrimeric protein that comprises 3 subunits, each of which has multiple phosphorylation sites that play critical roles in the regulation of either anabolism or catabolism by directly phosphorylating proteins or modulating gene transcription in multiple pathways, such as synthesis, oxidation and lipolysis of lipid. Research focused on the phosphorylation sites that are involved in lipid metabolism will lead to a better recognition of the role of AMPK in therapeutics for several common diseases. In this review, close attention is paid to the recent research on the structure, and multisite phosphorylation of AMPK subunits, as well as AMPK regulation of lipid metabolism via phosphorylation of related molecules.
\end{abstract}

Key words AMP-activated protein kinase (AMPK); lipid metabolism; phosphorylation; fatty acid; review

\section{INTRODUCTION}

AMP-activated protein kinase (AMPK) is a serine/threonine protein kinase that emerges as a sensor of cellular energy. ${ }^{1)}$ The compromised cellular energy status gives rise to an increase in the ratio of cellular AMP:ATP that activates AMPK and that AMPK also promotes its own $\alpha$ subunit phosphorylation at Thr172 through upstream kinases. In 1973, it was observed that AMPK activity was related to hydroxymethylglutaryl CoA reductase (HMGCR) and acetyl-CoA carboxylase (ACC), which are key modulators for cholesterol and fatty acid synthesis.,3) In eukaryotes such as mammals, AMPK is believed to act as a key master switch that modulates lipid metabolism by directly phosphorylating proteins or modulating gene transcription in specific tissues such as the liver, fat and muscle.

\section{AMPK SUBUNITS}

AMPK is a heterotrimeric protein kinase that is composed of $\alpha$ (isoforms $\alpha 1$ and $\alpha 2$ ), $\beta$ (isoforms $\beta 1$ and $\beta 2$ ) and $\gamma$ (isoforms $\gamma 1, \gamma 2$ and $\gamma 3$ ) subunits. The twelve different heterotrimeric holoenzymes consist from the combination of 2 alpha, 2 beta and 3 gamma subunits. The human $\alpha 1$ isoform (559 amino acids, 64kDa) and $\alpha 2$ isoform (552 amino acids, $62 \mathrm{kDa})$ are similar, each having an N-terminal kinase domain (KD), an autoinhibitory domain (AID, residues 302-381), two regulatory-subunit-interacting motifs (RIM) and a C-terminal $\beta / \gamma$ subunits binding domain. One tyrosine residue, 11 threonine residues and 14 serine residues within the $\alpha 1$ isoform have been identified, while three threonine residues and nine serine residues within the $\alpha 2$ isoform can be phosphorylated. Phosphorylation produces different effects on enzyme activity depending on the residue that is phosphorylated. AMPK is stimulated when it is phosphorylated at a conserved key

\footnotetext{
\# These authors contributed equally to this work.

threonine-172 residue in the N-terminal regions of the $\alpha 2$ subunit ( $\alpha 2$ threonine-172, equivalent to $\alpha 1$ threonine-183), ${ }^{4)}$ while the C-terminal domain is required to form complexes with the other two subunits. ${ }^{5)}$

The $\beta 1$ isoform consists of 270 amino acids $(30 \mathrm{kDa})$, including one myristoylated glycine residue, as well as two tyrosine residue, five threonine residues and 15 serine residues that can be phosphorylated. The $\beta 2$ isoform consists of 272 amino acids $(30 \mathrm{kDa})$, of which one tyrosine residue, two threonine residues and 13 serine residues can be phosphorylated.

The $\beta 1$ regulatory isoform has a carbohydrate-binding module (CBM, 96 amino acids) that mediates binding to glycogen, and a $\mathrm{C}$-terminal module that acts as a scaffold to allow binding of the $\alpha$ and $\gamma$ subunits. ${ }^{6)}$ Post-translational modification of the $\beta 1$ regulatory isoform is critical for its regulatory function. Removal of the myristoylated residue results in an increase in AMPK activity and has an effect on its redistribution from intracellular membrane to cytosol. AMPK activity also increases when the $\beta 1$ isoform is phosphorylated.' Moreover, it has been demonstrated that lysine262-sumoylation of the AMPK $\beta 2$ isoform also causes activation of AMPK. ${ }^{8)}$

The $\gamma 1$ regulatory isoform consists of 331 amino acids $(38 \mathrm{kDa})$ including one lysine residue that can be acetylated, as well as two threonine residues and six serine residues that can be phosphorylated. The $\gamma 2$ isoform consists of 569 amino acids $(63 \mathrm{kDa})$ with one tyrosine residue, four threonine residues and 20 serine residues that can be phosphorylated. The $\gamma 3$ isoform consists of 489 amino acids $(54 \mathrm{kDa})$, of which only one residue, a serine at position 65 , can be phosphorylated.

In the $\gamma$ subunit, four tandem cystathionine- $\beta$-synthase sequences (CBS motifs) consist of one or more copies of a conserved domain of $c a$. 60 amino acids forming two $\alpha$ helices and three $\beta$ strands. ${ }^{9)}$ CBS domains are numbered as CBS1 to CBS4, which are involved in AMP or ATP binding. ${ }^{10)}$ CBS1 (amino acids 43-103) and CBS3 (amino acids 198-260) bind ATP, ADP or AMP in a competitive manner depending on the cellular energy status. ${ }^{10)}$ CBS2 (amino acids 125-187) 


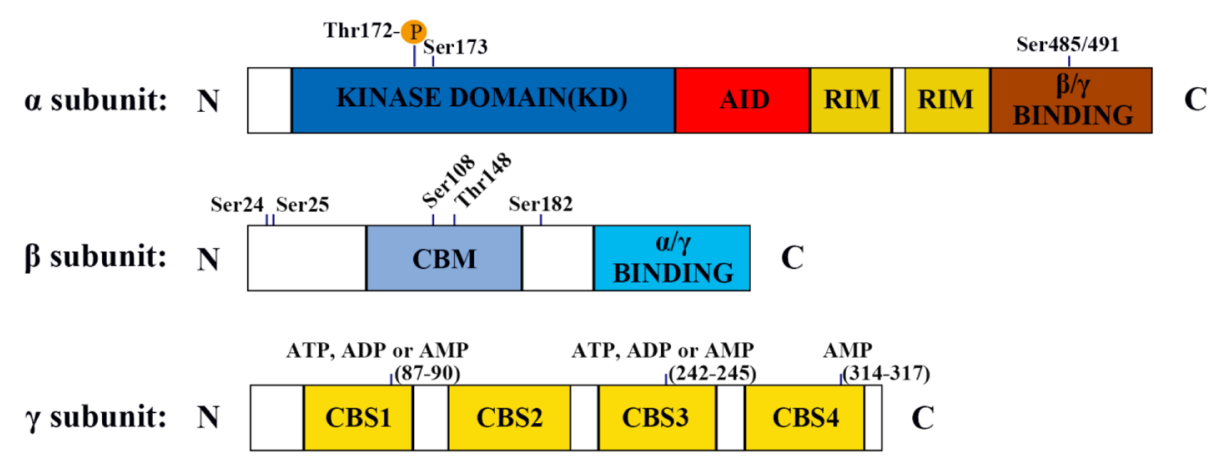

Fig. 1. Domain Structure of AMP-Activated Protein Kinase (AMPK) Subunit

The important phosphorylation sites in AMPK subunits are indicated. The positions of nucleotide binding to residues are shown within $\gamma$ subunit. AID, autoinhibitory domain; RIM, regulatory-subunit-interacting motifs; CBM, carbohydrate-binding module; CBS, cystathionine $\beta$ synthase repeats. (Color figure can be accessed in the online version.)

Table 1. Basic Information of AMPK Subunits, Isoforms

\begin{tabular}{|c|c|c|c|c|c|c|c|c|c|}
\hline \multirow[t]{2}{*}{ Isoforms } & \multirow{2}{*}{$\begin{array}{l}\text { Mass } \\
(\mathrm{kDa})\end{array}$} & \multirow{2}{*}{$\begin{array}{l}\text { Amino } \\
\text { acids }\end{array}$} & \multicolumn{3}{|c|}{$\begin{array}{c}\text { Number of } \\
\text { phosphorylation site }\end{array}$} & \multirow[t]{2}{*}{ Domain } & \multirow{2}{*}{$\begin{array}{l}\text { Domain } \\
\text { position }\end{array}$} & \multirow{2}{*}{$\begin{array}{c}\text { Tissue } \\
\text { expression }\end{array}$} & \multirow{2}{*}{$\begin{array}{l}\text { Chromosome } \\
\text { location }\end{array}$} \\
\hline & & & Tyr & Ser & Thr & & & & \\
\hline \multirow[t]{3}{*}{$\alpha 1$} & 64 & 559 & 1 & 14 & 11 & Catalytic domain & $27-279$ & Ubiquitous & $5 \mathrm{p} 13.1$ \\
\hline & & & & & & Autoinhibitory domain & $302-381$ & & \\
\hline & & & & & & C-Terminal domain & $393-559$ & & \\
\hline \multirow[t]{3}{*}{$\alpha 2$} & 62 & 552 & & 9 & 3 & Catalytic domain & $16-268$ & Heart & $1 \mathrm{p} 32.2$ \\
\hline & & & & & & Autoinhibitory domain & $291-376$ & Muscle & \\
\hline & & & & & & C-Terminal domain & $397-552$ & Kidney & \\
\hline \multirow[t]{2}{*}{$\beta 1$} & 30 & 270 & 2 & 15 & 5 & Carbohydrate-binding module & $68-163$ & Ubiquitous & $12 q 24.23$ \\
\hline & & & & & & C-Terminal domain & & Cytoplasm & \\
\hline \multirow[t]{2}{*}{$\beta 2$} & 30 & 272 & 1 & 13 & 2 & Carbohydrate-binding module & & Muscle & $1 \mathrm{q} 21.1$ \\
\hline & & & & & & C-Terminal domain & & & \\
\hline \multirow[t]{4}{*}{$\gamma 1$} & 38 & 331 & & 6 & 2 & Tandem repeat sequence 1 & $43-103$ & Ubiquitous & $12 q 13.12$ \\
\hline & & & & & & Tandem repeat sequence 2 & $125-187$ & & \\
\hline & & & & & & Tandem repeat sequence 3 & $198-260$ & & \\
\hline & & & & & & Tandem repeat sequence 4 & $272-329$ & & \\
\hline \multirow[t]{4}{*}{$\gamma 2$} & 63 & 569 & 1 & 20 & 4 & Tandem repeat sequence 1 & $275-335$ & Ubiquitous & $7 \mathrm{q} 36.1$ \\
\hline & & & & & & Tandem repeat sequence 2 & $357-415$ & Nucleus & \\
\hline & & & & & & Tandem repeat sequence 3 & $430-492$ & & \\
\hline & & & & & & Tandem repeat sequence 4 & $504-562$ & & \\
\hline \multirow[t]{4}{*}{$\gamma 3$} & 54 & 489 & & 1 & & Tandem repeat sequence 1 & $197-258$ & Muscle & $2 q 35$ \\
\hline & & & & & & Tandem repeat sequence 2 & $280-340$ & Heart & \\
\hline & & & & & & Tandem repeat sequence 3 & $355-415$ & Pancreas & \\
\hline & & & & & & Tandem repeat sequence 4 & $427-486$ & & \\
\hline
\end{tabular}

does not bind to a nucleotide but is closely related to ACC phosphorylation. ${ }^{11,12)}$ CBS4 (amino acids 272-329) strongly binds to AMP and may play a structural role. ${ }^{10,12)}$ When ATP levels decreased in the cell, AMP or ADP production relatively increased. And then AMP or ADP can bind to the CBS1 or CBS3 of $\gamma$ subunit, resulting in a conformational change that activates AMPK through phosphorylation at Thr172 in $\alpha$ subunit. ${ }^{13)}$ AMPK facilitates the generation of additional ATP by promoting catabolic pathways and inhibiting anabolic pathways, thus acting as a precise indicator of the cellular energy status (Fig. 1, Table 1).

\section{MULTISITE PHOSPHORYLATION OF AMPK SUBUNITS}

3.1. $\alpha$ and $\boldsymbol{\beta}$ Subunit Phosphorylation One site in the $\alpha$ subunit (Thr172) is the crucial for AMPK activation via phosphorylation by upstream kinases, which may include liver kinase B1 (LKB1), calmodulin-dependent kinase kinase (CaMKK), and transforming growth factor (TGF)- $\beta$-activated kinase-1 (TAK1). ${ }^{14-16)}$ The studies demonstrated that LKB1, in complex with two accessory subunits (Ste20-related Adapter $\alpha$ $(\mathrm{STRAD} \alpha)$ and Mouse protein $25 \alpha(\mathrm{MO} 25 \alpha))$, was required for AMPK activation in response to increased AMP, which may promote AMPK phosphorylation or inhibit AMPK dephosphorylation. ${ }^{17,18)}$ AMPK activity is also promoted by other AMPK kinases in cells with the lack of LKB1 expression. An increase in intracellular $\mathrm{Ca}^{2+}$ activates $\mathrm{CaMKK}$, which plays a physiological role in phosphorylating and activating AMPK. ${ }^{16)}$ The third AMPK kinase, TAK1, is a mediation in TGF $\beta$ signaling and it stimulated AMPK phosphorylation in mammalian cells. ${ }^{19)}$

Besides the active site Thr172, a number of sites also play indispensable roles in AMPK activity. One study reported 


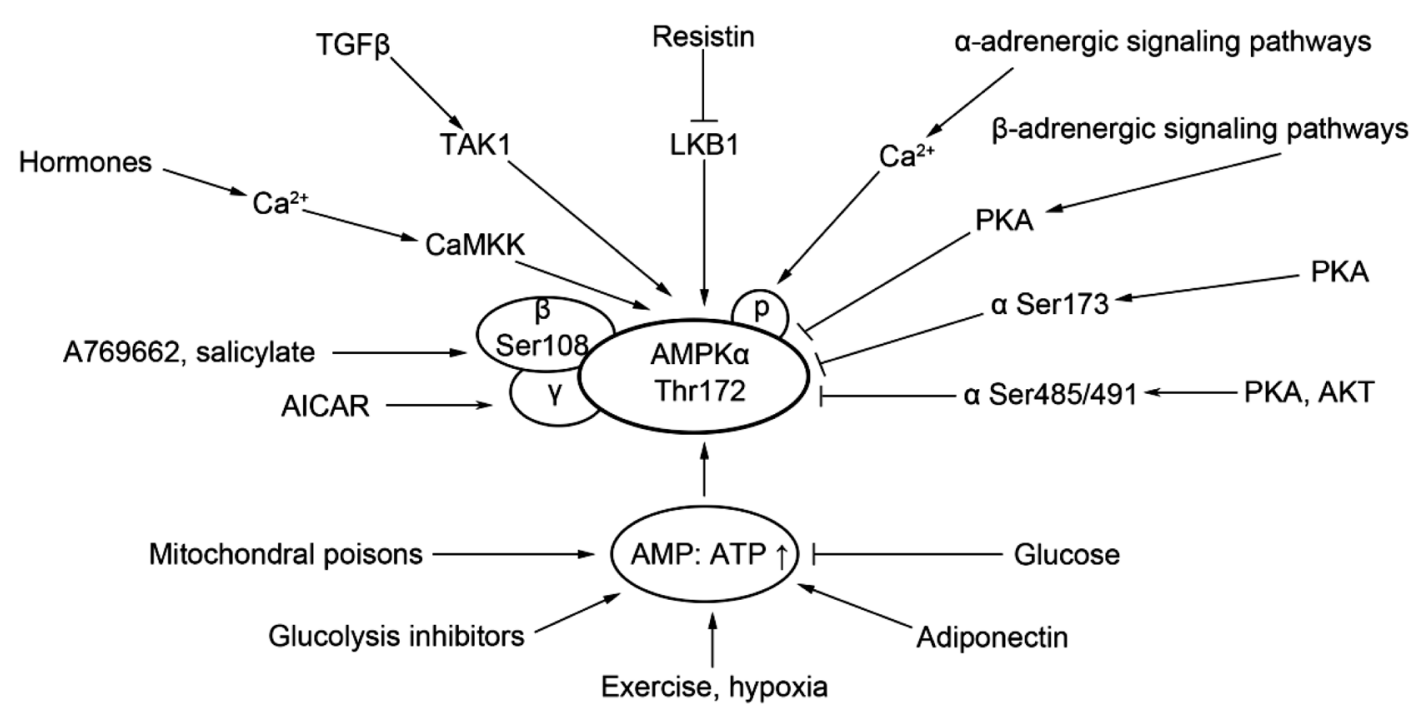

Fig. 2. AMP-Activated Protein Kinase (AMPK) Phosphorylation Is Regulated Not Only by the Upstream Kinases (LKB1, CaMKK, and TAK1), but Also by Many Metabolic Stresses That Interfere with AMP: ATP Ratio or Other Mechanisms

The phosphorylation at $\alpha$ Ser173, $\alpha$ Ser 485/491, and $\beta$ Ser108 also regulate AMPK activity. LKB1, liver kinase B1; CaMKK, calmodulin-dependent kinase kinase; TGF $\beta$, transforming growth factor $\beta$; TAK1, TGF- $\beta$-activated kinase-1; PKA, cAMP-dependent protein kinase; AKT, protein kinase B; AICAR, 5-aminoimidazole-4-carboxamide ribonucleotide. Activating interactions are marked with arrows and inhibitory connections with stoppers.

Table 2. Important Phosphorylation Site in AMPK Isoforms

\begin{tabular}{|c|c|c|c|c|}
\hline Isoforms & Phosphorylation site & Upstream kinase & Effect on protein function & References \\
\hline \multirow[t]{2}{*}{$\alpha 1$} & Thr183 ( $\alpha 2$ Thr172) & LKB1, CaMMK $\beta$, TAK1 & Activation & $4,13-19)$ \\
\hline & Ser485 & PKA, AKT & Inhibition & 20-22) \\
\hline \multirow[t]{3}{*}{$\alpha 2$} & Thr172 & LKB1, CaMMK $\beta$, TAK1 & Activation & $4,13-19)$ \\
\hline & Ser173 & PKA & Inhibition & 20) \\
\hline & Ser491 & PKA, AKT & Inhibition & 21-23) \\
\hline \multirow[t]{5}{*}{$\beta 1$} & Ser24 & PKA & Subcellular distribution & $7,20,32,33)$ \\
\hline & Ser25 & - & Subcellular distribution & $7,32,33)$ \\
\hline & Ser182 & - & Subcellular distribution & $7,32,33)$ \\
\hline & Ser108 & Autophosphorylation & Activation & $30-33)$ \\
\hline & Thr148 & Autophosphorylation & Subcellular distribution & 37) \\
\hline$\beta 2$ & Thr148 & Autophosphorylation & Subcellular distribution & $36,37)$ \\
\hline$\gamma 1$ & & & & \\
\hline$\gamma 2$ & & & & \\
\hline$\gamma 3$ & & & & \\
\hline
\end{tabular}

LKB1, liver kinase B1; CaMKK, calmodulin-dependent kinase kinase; TAK1, transforming growth factor (TGF)- $\beta$-activated kinase-1; PKA, cAMP-dependent protein kinase; AKT, protein kinase $B$.

that cAMP-dependent protein kinase (PKA) phosphorylated AMPK $\alpha 1$ at Ser173, resulting in its inhibition. ${ }^{20)}$ Multiple additional phosphorylation sites in the $\alpha$ subunit have also been studied. ${ }^{21)}$ The $\alpha 1$ Ser485 residue is involved in negative regulation of AMPK by cAMP-PKA. ${ }^{22)}$ In additional, phosphorylation of AMPK $\alpha$ Ser485/491, when stimulated with insulin, has been shown to lead to a decrease in AMPK activity. ${ }^{23)}$ AMPK activity is also regulated by many metabolic stresses that disrupt the ratio of AMP:ATP, including mitochondrial poisons (thiazolidinediones, biguanides, and resveratrol), glycolysis inhibitors (2-deoxyglucose), exercise, hypoxia, and adiponectin. ${ }^{2425)}$ Moreover, AMPK can be activated in response to other agents. 5-Aminoimidazole-4-carboxamide ribonucleotide (AICAR) directly activates AMPK through binding to thersubunit. ${ }^{26)}$ Resistin decreases phosphorylation of LKB1, and subsequently decreases phosphorylation of AMPK. ${ }^{27)}$ The $\alpha / \beta$-adrenergic stimulation may lead to AMPK activation by stimulating the upstream signaling of AMPK. Intracellular $\beta$-adrenergic signaling pathways, via a $\mathrm{G}$ protein activate the downstream enzyme, PKA, ${ }^{28)}$ while the $\alpha$-adrenergic agonists activate $\mathrm{Ca}^{2+}$ signaling in rat cells. ${ }^{29)}$ Additionally, like AMP, a smallmolecule activator of AMPK, A769662, directly activated AMPK by allosteric activation and inhibition of dephosphorylation of Thr172. However, A769662 activated AMPK harboring a mutation within the $\gamma$ subunit that counteracted activation by AMP. And the mutation of Ser108 in the region of the $\beta 1$ subunit termed CBM almost completely neutralized activation of AMPK by A769662, while only partially impairing AMP activation. These provided evidence that the mechanisms of activation by AMP and A769662 are different. ${ }^{30}$ Surprisingly, an ancient drug, salicylate, was also found to directly activate AMPK by binding the same site as A769662. Both salicylate and A769662 need the CBM of AMPK $\beta 1$ and its phosphorylation at Ser108 to activate AMPK without increasing cellular ADP : ATP ratio, indicating an AMP independent mechanism ${ }^{31}$ (Fig. 2). Besides Ser108, Ser24/25, and 
Ser182 can be also partially phosphorylated in the AMPK $\beta 1$ subunit. ${ }^{32,33)}$ The mutants of Ser24/25 and Ser182 does not disrupt AMPK activity, but results in the nuclear redistribution of the holoenzyme ${ }^{7)}$ (Table 2).

To date, most studies of AMPK autophosphorylation sites have focused the $\beta$-subunits. Autophosphorylation of Ser24/25, Ser108, Ser96, Ser101 and Thr148 within the $\beta$ subunit have been reported..$^{32,34-36)}$ Autophosphorylation of Thr148 in AMPK $\beta 1 / \beta 2$ leads to a loss of carbohydrate binding ability. As a switch, it plays a role in regulating the subcellular localization of AMPK. ${ }^{37}$ ) Moreover, AMPK $\alpha$ Ser485/491, which was confirmed by using recombinant protein, ${ }^{35)}$ was also autophosphorylated to limit AMPK activation in response to energy depletion or other regulators. ${ }^{21)}$ The functional roles of additional AMPK autophosphorylation sites, such as $\alpha 1$ Thr477, $\alpha 1$ Ser349, $\beta 1$ Thr158, and $\beta 1$ Thr80, ${ }^{38)}$ requires further investigation.

3.2. $\gamma$ Subunit Phosphorylation Phosphorylation of the $\gamma$ subunit has rarely been reported. One study, which explored the effects of an R225Q mutation in the AMPK $\gamma 3$ subunit, showed increased basal AMPK phosphorylation that was accompanied by a reduction in sensitivity to AMP. The effects of this mutation on insulin resistance and dietaryinduced triacylglycerol (TG) accumulation were explored in AMPK $\gamma 3$ R225Q transgenic mice. However, the effect of the R225Q mutation on AMPK activity was inadequate to remit obesity and insulin resistance in mice with leptin deficiency. Leptin insufficiency leads to the lack of central leptin signaling, and the metabolic benefit from AMPK $\gamma 3$ R225Q mutation was overridden. ${ }^{39)}$ Recently, an additional study observed that an AMPK $\gamma 2$ R299Q mutation in mice caused obesity and reduced insulin secretion, which may provide new insights to drug targets. ${ }^{40)}$

\section{AMPK-MEDIATED REGULATION OF PROTEINS INVOLVED IN LIPID METABOLISM}

In liver and adipose tissue, surplus energy is stored as TG by the fatty acid pathway. Fatty acids can be oxidized to provide energy during times of energy deficiency. When fatty acids are absorbed across the plasma membrane, they are activated to fatty acyl-CoA, which can either be stored or oxidized. The genes that encode ACC1, fatty acid synthase (FASN) and stearoyl-CoA desaturase (SCD)1, which are targeted by the transcription factor sterol regulatory element binding protein 1c (SREBP1c), are lipogenic enzymes that promote the de novo synthesis of cytoplasmic fatty acids. ACC1 can catalyse the carboxylation of acetyl-CoA to malonyl-CoA, which is the main substrate of FASN. FASN catalyzes the de novo synthesis of long-chain fatty acids in the cytosol through the condensation of acyl-CoA and malonyl-CoA. FASN causes increased synthesis of saturated fatty acids, which are converted into monounsaturated fatty acids by SCD1. The final step of this process is TG synthesis from long-chain fatty acids. Mitochondrial glycerol-3-phosphate acyltransferase (GPAT) lies on the mitochondrial outer membrane, which channels acyl-CoAs towards the synthetic pathways. Unlike hormone-sensitive lipase (HSL), mitochondrial GPAT plays a pivotal role in preventing fatty acids from undergoing $\beta$-oxidation by converting acyl-CoA into lysophosphatidate. Adipose triglyceride lipase (ATGL) and HSL are the key enzymes acting successively on lipolysis. When lipolysis occurs, TG can be hydrolysed into glycerol and fatty acids that can be transferred back to the blood. Sequentially, fatty acids can be oxidized to provide energy. Malonyl-CoA is a vital regulatory factor of fatty acid oxidation in liver and it is a potent inhibitor of carnitine acyltransferase I (CPT1), which is allosterically suppressed to reduce the $\beta$-oxidation of fatty acid in mitochondria. The inhibition of ACC2 causes the reduced malonyl-CoA, sequentially promotes CPT1, leading to the increased transport of acyl-CoA to mitochondria and the $\beta$-oxidation. Recent reports have suggested that AMPK modulates lipid synthesis, lipolysis, and fatty acid oxidation through phosphorylation of key substrates, as discussed below (Fig. 3).

4.1. ACC Nearly 4 decades ago, AMPK regulation of ACC activity was first observed. ACC is an important site of regulation within the fatty acid synthesis and oxidation pathways, as it can catalyse the carboxylation of acetyl-CoA to malonyl-CoA during the synthesis of fatty acids or allosterically inhibit CPT-1, a key enzyme for $\beta$-oxidation. ${ }^{41)}$ ACC consists of both ACC1 and ACC2 isoforms. Data have accumulated that show $\mathrm{ACC} 1$ is involved in the regulation of fatty acid synthesis, unlike ACC2, which has a 146-amino acid Nterminal region that directs its localization in mitochondria to inhibit the oxidation of fatty acids. Malonyl-CoA synthesized by ACC2 allosterically inhibits CPT1 to reduce $\beta$-oxidation in mitochondria. When purified from lactating rat mammary glands or rat liver, ACC was observed to be phosphorylated by purified AMPK at three sites: Ser79, Ser1200 and Ser1215. Moreover, Ser79 was observed to be responsible for the inactivation of $\mathrm{ACC} 1$ by AMPK, after which phospho-ACC1 Ser79 became a universal indicator of AMPK activity. ${ }^{42,43)}$ In ACC2, Ser219 is the equivalent of Ser79 in ACC1 because of the N-terminal extension. ACC2 activity is inhibited by the phosphorylation of Ser219 by AMPK. It was shown that a lower malonyl-CoA level that was accompanied by increased fatty acid oxidation was associated with decreased ACC2 activity in mouse skeletal muscle. ${ }^{44}$ Moreover, studies on the fruit fly Drosophila melanogaster showed that AMPK increased the phosphorylation of Ser-93 in ACC. ${ }^{45}$ ) The identification of sites of AMPK phosphorylation in human ACC1 (Ser80 and Ser1216) and yeast ACC (Ser1157) have enhanced our understanding of ACC regulation by phosphorylation. Phosphorylation of Ser80 in human ACC1 and Ser1157 in yeast ACC have been reported to stabilize inactive ACC conformations by facilitating the dissociation of the biotin carboxylase domain dimer and stabilizing the monomeric form of the biotin carboxylase domain, which repressed the catalytic activity of ACC. ${ }^{46)}$

4.2. SREBP Consistent with the above-mentioned study, activation of AMPK $\alpha$ was observed to reduce TG accumulation in the hepatocytes, ${ }^{47)}$ where $\mathrm{ACC} 1,{ }^{48)}$ a downstream substrate of AMPK, inhibited fatty acid synthesis. The genes that encode ACC1 and other lipogenic enzymes, such as FASN, and SCD1, are targeted by SREBP1c, ${ }^{49)}$ a member of the SREBP family.

SREBPs comprise a family of transcription factors with three isoforms (SREBP1a, SREBP1c and SREBP2), which modulate the expression of enzymes involved in the synthesis of fatty acids, TG, phospholipids, and cholesterol. ${ }^{50)}$ As a key transcription factor, SREBP1c directly promotes the expression of over 30 genes that facilitate fatty acid uptake and TG 


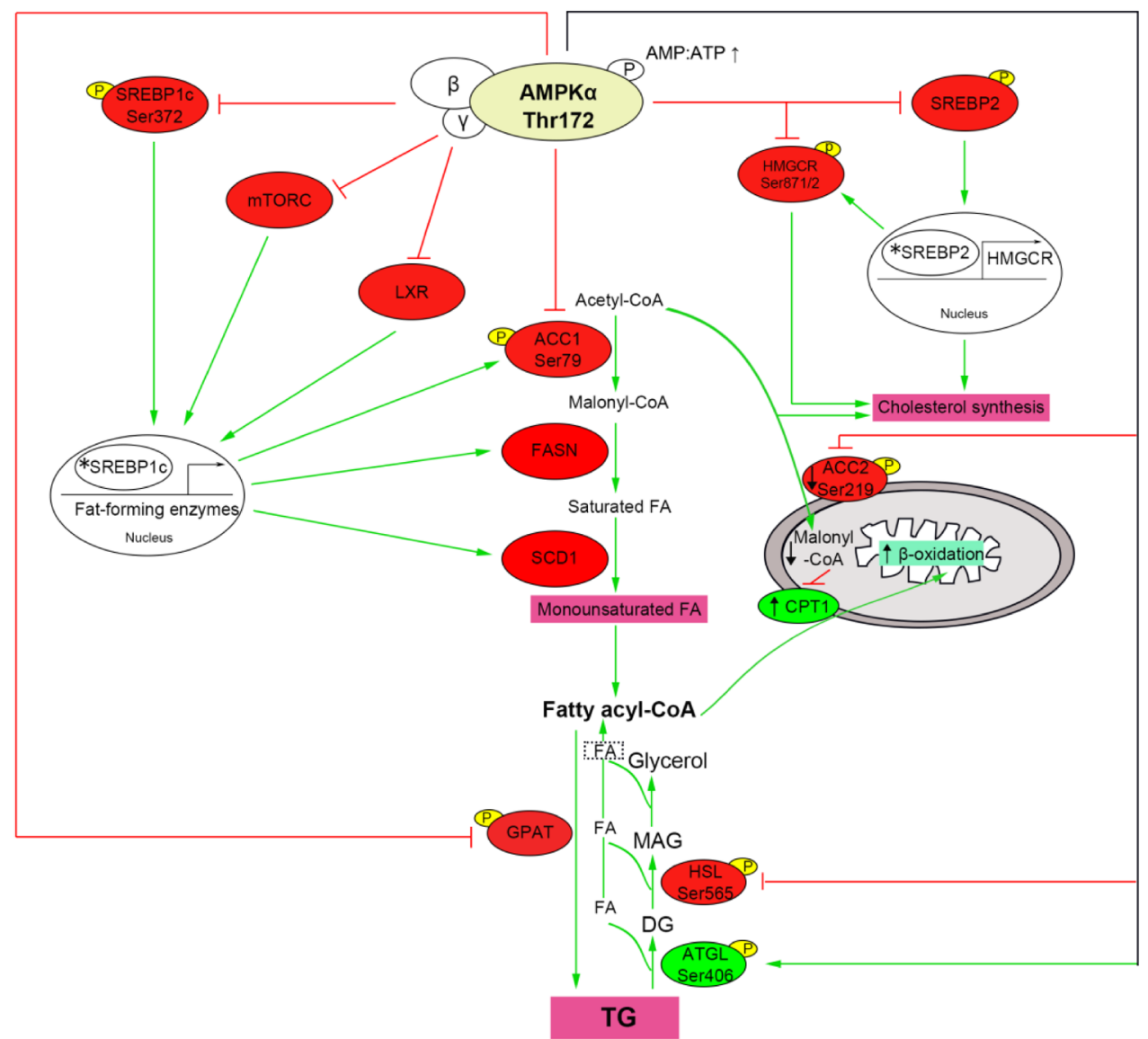

Fig. 3. AMP-Activated Protein Kinase (AMPK) Plays Critical Roles in the Regulation of Either Anabolism or Catabolism by Directly Phosphorylating Proteins or Modulating Gene Transcription in Multiple Pathways, Such as Synthesis, Oxidation and Lipolysis of Lipid

The phosphorylation sites of the related lipogenic molecules are mentioned in the present review. TG, triacylglycerol; DG, diacylglycerol; MAG, monoacylglycerol; FA, fatty acid; ACC, acetyl-CoA carboxylase; FASN, fatty acid synthase; SCD1, stearoyl-CoA desaturase 1; SREBP, sterol regulatory element binding protein; GPAT, glycerol3-phosphate acyltransferase; HSL, hormone-sensitive lipase; ATGL, adipose triglyceride lipase; HMGCR, hydroxy-methylglutaryl coenzyme A reductase; mTORC, mammalian target of rapamycin complex; LXR, liver X receptor. Activating interactions are marked with green arrows and inhibitory connections with red stoppers. The color circles/boxes indicated whether that general process is activated (green) or inhibited (red) by AMPK. The dotted box indicated potentially ambiguous regulation. AMPKmediated phosphorylation events were in yellow. Transcriptional regulators are denoted by an asterisk. Descending arrows indicated ACC 2 inhibition and malonyl-CoA reduction; ascending arrows depicted CPT1 activation and the increase of $\beta$-oxidation. (Color figure can be accessed in the online version.)

synthesis. ${ }^{51)}$ SREBPs can be modified by phosphorylation to regulate their stability and/or transcriptional activity. ${ }^{52-54)}$ A number of post-translational modifications of SREBP1, including phosphorylation at Thr426, Ser430 or Ser410, have been shown to be related to SREBP1c activity. ${ }^{55)} \mathrm{Li}$ et al. showed that SREBP1c was directly phosphorylated by AMPK and associated with reduction of nuclear SREBP1c. AMPK was shown to phosphorylate SREBP1c at Ser372, suppressing the proteolytic cleavage of precursor SREBP1c into mature SREBP1c, leading to the suppression of hepatic steatosis in diet-induced insulin-resistant mice. ${ }^{56)}$ In addition to direct regulation, AMPK can further reduce hepatic lipid contents by suppressing SREBP1c expression through decreasing the activity of mammalian target of rapamycin complex (mTORC), ${ }^{57,58)}$ an important mediator for the regulation of cellular metabolism and growth that may also promote SREBP-dependent fatty acid synthesis. mTORC1-dependent activation of SREBP1c is thought to accelerate fatty acid synthesis by cleavage of the SREBP1c molecule. ${ }^{59)}$ mTORC2 is also required for the coordinated regulation of insulin-induced glycolysis and lipogenesis by glucokinase and SREBP1c. ${ }^{60}$ Moreover, activation of AMPK may also suppress the transcriptional activity of downstream targets, such as liver $\mathrm{X}$ re- ceptors (LXRs), which is an upstream transcription factor that increase SREBP1c activity ${ }^{61)}$ to promote fatty acid synthesis. ${ }^{62)}$ AMPK suppresses SREBP1c expression through these targets, reducing FASN expression, and subsequently inhibiting lipid synthesis.

SREBP2 is the primary transcriptional regulator in cholesterol metabolism, and preferentially activates the expression of 12 enzymes involved in cholesterol biosynthesis. ${ }^{63)}$ Shortterm chronic activation of AMPK led to a 1.6-fold increase of SREBP2 mRNA in the transgenic liver that selectively expressed constitutively active AMPK, ${ }^{64)}$ while SREBP2 mRNA levels fell by $70 \%$ in white adipose tissue. ${ }^{65)}$ In addition, AMPK decreased the nuclear translocation of SREBP2 in hepatic cells. ${ }^{66)}$ A recent research study observed that AMPK suppressed SREBP2 activity by direct phosphorylation, which impeded the accumulation of nuclear SREBP2, repressed the expression of its downstream targets, and ameliorated dyslipidemia. ${ }^{56)}$ In another study, an immunoprecipitation and immunoblot analysis with specific antibodies showed that AMPK phosphorylated threonine residues of the SREBP2 precursor and nuclear forms in HepG2 cells, LO2 cells, and in TSH receptor knockout mice. ${ }^{67)}$ Future research will require that the specific AMPK-induced phosphorylation sites 
in SREBP2 be identified. Moreover, Wang et al. observed that the intracellular cholesterol was increased and high levels of SREBP2 and HMGCR mRNA were present in a timedependent manner in steatotic hepatocytes, suggesting that the increased intracellular cholesterol was probably a result of the upregulation of SREBP2 and its target genes. ${ }^{50)}$ HMGCR is the most important target of SREBP2. ${ }^{63)}$ It was suggested that AMPK activation decreased cleavage of SREBP2 in dietinduced insulin-resistant $\mathrm{LDLR}^{-/-}$mice that were treated with the synthetic polyphenol S17834 and reduced the expression of the downstream targets, such as HMGCR. ${ }^{56)}$ Another study also suggested that AICAR-induced activation of AMPK suppressed the expression of the genes encoding HMGCR and hydroxy-methylglutaryl CoA synthase (HMGCS), which was associated with reduced expression of SREBP2. ${ }^{67)}$

4.3. GPAT TG synthesis is inhibited by pre-treatment with AICAR, an AMPK activator, which could decrease the incorporation of fatty acids into TG. ${ }^{51)}$ GPAT, which exists in microsomal and the mitochondrial isoforms, catalyses the formation of lysophosphatidic acid from long chain acyl-CoA and glycerol-3-phosphate, and it is the rate-limiting enzyme that catalyses the first and critical step in TG synthesis. ${ }^{68)}$ GPAT activity and TG biosynthesis in the liver have been inhibited by AMPK activation.

GPAT has four dominating isoforms (GPAT1-GPAT4). GPAT1 and GPAT2 lie in the outer mitochondrial membrane, and the other two are the isoforms of endoplasmic reticulum. Among them, three (in addition to GPAT1) are suppressed by $N$-ethylmaleimide (NEM), which is a significant contributor to TG synthesis. All four isoforms take part in the glycerolipid biosynthetic pathway, working in coordination for TG synthesis. One study showed that the overexpression of mitochondrial GPAT, which is primarily expressed in the liver, led to a dramatic $80 \%$ reduction in fatty acid oxidation and a significant increase in hepatic diacylglycerol and phospholipid biosynthesis, resulting in a significant increase in intracellular TG synthesis. ${ }^{69)}$ In hepatocytes, AMPK-mediated phosphorylation of mitochondrial GPAT leads to its inactivation. ${ }^{70)}$ Following exercise, GPAT activity appears to be inhibited by an increase in AMPK activity ${ }^{70,71)}$ by the administration of AICAR in the liver and epididymal fat, but not in muscle. ${ }^{72)}$ A very low activity of GPAT in muscle was also observed in another study, ${ }^{70)}$ in which the effects of AICAR or AMPK on muscle GPAT activities in this tissue could not be directly tested, although TG synthesis was substantially inhibited. Therefore, the liver is the primary organ for GPAT regulation with respect to intracellular TG biosynthesis. Moreover, Muoio et al. suggested that when cellular ATP levels were compromised, inactivation of mitochondrial GPAT, mediated by AMPK, served to conserve energy by suppressing TG synthesis and eliminating the direct competitor of CPT1 for acylCoA substrates, which may potentiate fatty acid entry into the mitochondria. ${ }^{70)}$ GPAT gene expression was also suppressed in the presence of an AMPK inhibitor, compound $\mathrm{C}$, which subsequently reduced TG accumulation. ${ }^{73)}$

4.4. HSL There are three stages occurring in the TG lipolysis, accompanying with key enzymes acting on different steps. ATGL catalyzes the hydrolysis of TG to generate diacylglycerol (DG). HSL exhibits as a DG hydrolase by primary converting DG to monoacylglycerol (MAG). Finally MAG is hydrolyzed to release glycerol. Among them, fatty acid is lib- erated at each stage.

HSL is considered as a rate-limiting enzyme in TG hydrolysis, and is the major lipase that regulates catecholamine- and natriuretic peptide-induced lipolysis. Experiments have suggested that PKA phosphorylates HSL at Ser563 and Ser660 to activate HSL for lipolysis in adipose tissue, which is essential for HSL translocation to lipid droplets in response to lipolytic stimuli. Additionally, AICAR-induced AMPK could phosphorylate HSL at Ser565 to inhibit HSL Ser660 and Ser563 phosphorylation, reducing HSL activity and significantly suppressing lipolysis in adipocytes. ${ }^{74,75)}$ These data demonstrate that AMPK inhibits HSL by phosphorylation, that phosphorylated HSL is unable to translocate to lipid droplets in AMPK $\alpha 1$ knock-out mice and in primary rodent adipocytes and in 3T3-L1 adipocytes by using pharmacological activators or with adenovirus that constitutively expresses active or dominant negative forms of AMPK. ${ }^{76)}$ However, the role of AMPK in the regulation of TG lipolysis in adipocytes was controversial. $^{76,77)}$ AMPK may phosphorylate Ser406 of ATGL to stimulate TG hydrolase activity and activate lipolysis. ${ }^{78)}$ AMPK can promote lipolysis under basal conditions by increasing desnutrin/ATGL phosphorylation. Nevertheless, under stimulated conditions, AMPK decreases HSL activity in adipose tissue, leading to an inhibition of lipolysis, but free fatty acid release increased. ${ }^{79)}$ Moreover, one study reported that HSL Ser563 phosphorylation, activity and lipolysis were not inhibited by AMPK activation during exercise. ${ }^{80)}$ However, activated AMPK was shown to be involved in suppressing the activity of HSL, overriding $\beta$-adrenergic stimulation of TG lipolysis. ${ }^{81)}$ This discrepancy may be associated with tissue-specific function of AMPK at different conditions.

4.5. HMGCR HMGCR is a key rate-limiting enzyme in the cholesterol biosynthetic pathway. Because of the involvement of cholesterol in the development of atherosclerosis and cardiovascular disease, regulating HMGCR has been a subject of great interest. Its activity may be regulated by the equilibrium between enzyme phosphorylation and dephosphorylation, where phosphorylation inactivates the enzyme. HMGCR phosphorylation, which occurs at Ser871 in rodents and Ser872 in humans, is of crucial importance in regulating hepatic cholesterol biosynthesis. In additional to protein kinase $\mathrm{C}$ (PKC) and a $\mathrm{Ca}^{2+} /$ calmodulin-dependent protein kinase, AMPK is an important HMGCR kinase in the rat liver and copurifies with ACC kinase activity. When phosphorylated at Thr172, AMPK is activated and can phosphorylate HMGCR, leading to its inactivity. Recently, Zhang et al. ${ }^{82)}$ observed that AMPK activation of HMGCR was inhibited by HMGCR phosphorylation at Ser872, establishing a potential mechanism for hypercholesterolemia.

\section{CONCLUSION}

It is well known that AMPK plays a vital role in the development and treatment of diabetes, obesity, and metabolic syndromes with respect to the above-mentioned effects of AMPK on lipid metabolism. In this review, we explored several aspects of AMPK, such as its structure, multisite phosphorylation of subunits and its regulation of the phosphorylation of key molecules involved in lipid metabolism. Furthermore, studies on the potential mechanisms of AMPK-mediated modulation of lipid metabolism are required for exploration in 
greater detail. The information will tremendously help in the design of drugs to treat obesity and metabolic syndromes.

Conflict of Interest The authors declare no conflict of interest.

\section{REFERENCES}

1) Grahame Hardie D. Regulation of AMP-activated protein kinase by natural and synthetic activators. Acta Pharmaceutica Sinica B, 6, $1-19$ (2016).

2) Beg ZH, Allmann DW, Gibson DM. Modulation of 3-hydroxy3-methylglutaryl coenzyme A reductase activity with cAMP and wth protein fractions of rat liver cytosol. Biochem. Biophys. Res. Commun., 54, 1362-1369 (1973).

3) Carlson CA, Kim KH. Regulation of hepatic acetyl coenzyme A carboxylase by phosphorylation and dephosphorylation. J. Biol. Chem., 248, 378-380 (1973).

4) Novikova DS, Garabadzhiu AV, Melino G, Barlev NA, Tribulovich VG. AMP-activated protein kinase: structure, function, and role in pathological processes. Biochemistry. Biokhimiia, 80, 127-144 (2015).

5) Iseli TJ, Walter $M$, van Denderen BJ, Katsis F, Witters LA, Kemp BE, Michell BJ, Stapleton D. AMP-activated protein kinase beta subunit tethers alpha and gamma subunits via its C-terminal sequence (186-270). J. Biol. Chem., 280, 13395-13400 (2005).

6) Hudson ER, Pan DA, James J, Lucocq JM, Hawley SA, Green KA, Baba O, Terashima T, Hardie DG. A novel domain in AMP-activated protein kinase causes glycogen storage bodies similar to those seen in hereditary cardiac arrhythmias. Curr. Biol., 13, 861-866 (2003).

7) Warden SM, Richardson C, O'Donnell J Jr, Stapleton D, Kemp BE, Witters LA. Post-translational modifications of the $\beta$-1 subunit of AMP-activated protein kinase affect enzyme activity and cellular localization. Biochem. J., 354, 275-283 (2001).

8) Rubio T, Vernia S, Sanz P. Sumoylation of AMPK $\beta 2$ subunit enhances AMP-activated protein kinase activity. Mol. Biol. Cell, 24, 1801-1811, S1-S4 (2013).

9) Bateman A. The structure of a domain common to archaebacteria and the homocystinuria disease protein. Trends Biochem. Sci., 22, 12-13 (1997)

10) Xiao B, Heath R, Saiu P, Leiper FC, Leone P, Jing C, Walker PA, Haire L, Eccleston JF, Davis CT, Martin SR, Carling D, Gamblin SJ. Structural basis for AMP binding to mammalian AMP-activated protein kinase. Nature, 449, 496-500 (2007).

11) Scott JW, Ross FA, Liu JK, Hardie DG. Regulation of AMP-activated protein kinase by a pseudosubstrate sequence on the $\gamma$ subunit. EMBO J., 26, 806-815 (2007).

12) Townley R, Shapiro L. Crystal structures of the adenylate sensor from fission yeast AMP-activated protein kinase. Science, 315, 1726-1729 (2007).

13) Xiao B, Sanders MJ, Underwood E, Heath R, Mayer FV, Carmena D, Jing C, Walker PA, Eccleston JF, Haire LF, Saiu P, Howell SA, Aasland R, Martin SR, Carling D, Gamblin SJ. Structure of mammalian AMPK and its regulation by ADP. Nature, 472, 230-233 (2011).

14) Chen Z, Shen $X$, Shen F, Zhong W, Wu H, Liu S, Lai J. TAK1 activates AMPK-dependent cell death pathway in hydrogen peroxidetreated cardiomyocytes, inhibited by heat shock protein-70. Mol. Cell. Biochem., 377, 35-44 (2013).

15) Shaw RJ, Lamia KA, Vasquez D, Koo SH, Bardeesy N, Depinho RA, Montminy M, Cantley LC. The kinase LKB1 mediates glucose homeostasis in liver and therapeutic effects of metformin. Science, 310, 1642-1646 (2005)

16) Woods A, Dickerson K, Heath R, Hong SP, Momcilovic M, Johnstone SR, Carlson M, Carling D. $\mathrm{Ca}^{2+} /$ calmodulin-dependent pro- tein kinase kinase-beta acts upstream of AMP-activated protein kinase in mammalian cells. Cell Metab., 2, 21-33 (2005).

17) Sanders MJ, Grondin PO, Hegarty BD, Snowden MA, Carling D. Investigating the mechanism for AMP activation of the AMPactivated protein kinase cascade. Biochem. J., 403, 139-148 (2007).

18) Hawley SA, Boudeau J, Reid JL, Mustard KJ, Udd L, Makela TP, Alessi DR, Hardie DG. Complexes between the LKB1 tumor suppressor, STRAD $\alpha / \beta$ and $\mathrm{MO} 25 \alpha / \beta$ are upstream kinases in the AMP-activated protein kinase cascade. J. Biol., 2, 28 (2003).

19) Momcilovic M, Hong SP, Carlson M. Mammalian TAK1 activates Snf1 protein kinase in yeast and phosphorylates AMP-activated protein kinase in vitro. J. Biol. Chem., 281, 25336-25343 (2006).

20) Djouder N, Tuerk RD, Suter M, Salvioni P, Thali RF, Scholz R, Vaahtomeri K, Auchli Y, Rechsteiner H, Brunisholz RA, Viollet B, Makela TP, Wallimann T, Neumann D, Krek W. PKA phosphorylates and inactivates AMPKalpha to promote efficient lipolysis. EMBO J., 29, 469-481 (2010).

21) Hurley RL, Barre LK, Wood SD, Anderson KA, Kemp BE, Means AR, Witters LA. Regulation of AMP-activated protein kinase by multisite phosphorylation in response to agents that elevate cellular cAMP. J. Biol. Chem., 281, 36662-36672 (2006).

22) He L, Chang E, Peng J, An H, McMillin SM, Radovick S, Stratakis CA, Wondisford FE. Activation of the cAMP-PKA pathway antagonizes metformin suppression of hepatic glucose production. J. Biol. Chem., 291, 10562-10570 (2016).

23) Valentine RJ, Coughlan KA, Ruderman NB, Saha AK. Insulin inhibits AMPK activity and phosphorylates AMPK $\mathrm{Ser}^{485 / 491}$ through Akt in hepatocytes, myotubes and incubated rat skeletal muscle. Arch. Biochem. Biophys., 562, 62-69 (2014).

24) Kahn BB, Alquier T, Carling D, Hardie DG. AMP-activated protein kinase: ancient energy gauge provides clues to modern understanding of metabolism. Cell Metab., 1, 15-25 (2005).

25) Kola B, Boscaro M, Rutter GA, Grossman AB, Korbonits M. Expanding role of AMPK in endocrinology. Trends Endocrinol. Metab., 17, 205-215 (2006).

26) Hardie DG. AMP-activated protein kinase as a drug target. Annu. Rev. Pharmacol. Toxicol., 47, 185-210 (2007).

27) Liu P, Cheng GC, Ye QH, Deng YZ, Wu L. LKB1/AMPK pathway mediates resistin-induced cardiomyocyte hypertrophy in $\mathrm{H} 9 \mathrm{c} 2 \mathrm{em}-$ bryonic rat cardiomyocytes. Biomedical Reports, 4, 387-391 (2016).

28) Jozwiak-Bebenista M, Wiktorowska-Owczarek A, Kowalczyk E. $\beta$-Adrenoceptor-mediated cyclic AMP signal in different types of cultured nerve cells in normoxic and hypoxic conditions. Molekuliarnaia Biologiia, 50, 838-846 (2016).

29) Assimacopoulos-Jeannet FD, Blackmore PF, Exton JH. Studies on $\alpha$-adrenergic activation of hepatic glucose output. Studies on role of calcium in $\alpha$-adrenergic activation of phosphorylase. J. Biol. Chem., 252, 2662-2669 (1977).

30) Sanders MJ, Ali ZS, Hegarty BD, Heath R, Snowden MA, Carling D. Defining the mechanism of activation of AMP-activated protein kinase by the small molecule A-769662, a member of the thienopyridone family. J. Biol. Chem., 282, 32539-32548 (2007).

31) Hawley SA, Fullerton MD, Ross FA, Schertzer JD, Chevtzoff C, Walker KJ, Peggie MW, Zibrova D, Green KA, Mustard KJ, Kemp BE, Sakamoto K, Steinberg GR, Hardie DG. The ancient drug salicylate directly activates AMP-activated protein kinase. Science, 336, 918-922 (2012).

32) Mitchelhill KI, Michell BJ, House CM, Stapleton D, Dyck J, Gamble J, Ullrich C, Witters LA, Kemp BE. Posttranslational modifications of the 5'-AMP-activated protein kinase betal subunit. J. Biol. Chem., 272, 24475-24479 (1997).

33) Wang Y, Fan Q, Ma R, Lin W, Tang T. Gene expression profiles and phosphorylation patterns of AMP-activated protein kinase subunits in various mesenchymal cell types. Chin. Med. J., 127, 2451-2457 (2014).

34) Chen Z, Heierhorst J, Mann RJ, Mitchelhill KI, Michell BJ, Witters 
LA, Lynch GS, Kemp BE, Stapleton D. Expression of the AMP-activated protein kinase $\gamma 1$ and $\beta 2$ subunits in skeletal muscle. $F E B S$ Lett., 460, 343-348 (1999).

35) Woods A, Vertommen D, Neumann D, Turk R, Bayliss J, Schlattner U, Wallimann T, Carling D, Rider MH. Identification of phosphorylation sites in AMP-activated protein kinase (AMPK) for upstream AMPK kinases and study of their roles by site-directed mutagenesis. J. Biol. Chem., 278, 28434-28442 (2003).

36) Oligschlaeger Y, Miglianico M, Dahlmans V, Rubio-Villena $C$, Chanda D, Garcia-Gimeno MA, Coumans WA, Liu Y, Voncken JW, Luiken JJ, Glatz JF, Sanz P, Neumann D. The interaction between AMPK $\beta 2$ and the PP1-targeting subunit R6 is dynamically regulated by intracellular glycogen content. Biochem. J., 473, 937-947 (2016).

37) Oligschlaeger $Y$, Miglianico $M$, Chanda D, Scholz R, Thali RF, Tuerk R, Stapleton DI, Gooley PR, Neumann D. The recruitment of AMP-activated protein kinase to glycogen is regulated by autophosphorylation. J. Biol. Chem., 290, 11715-11728 (2015).

38) Tuerk RD, Auchli Y, Thali RF, Scholz R, Wallimann T, Brunisholz RA, Neumann D. Tracking and quantification of 32P-labeled phosphopeptides in liquid chromatography matrix-assisted laser desorption/ionization mass spectrometry. Anal. Biochem., 390, 141-148 (2009).

39) Zachariah Tom R, Garcia-Roves PM, Sjogren RJ, Jiang LQ, Holmstrom MH, Deshmukh AS, Vieira E, Chibalin AV, Bjornholm M, Zierath JR. Effects of AMPK activation on insulin sensitivity and metabolism in leptin-deficient ob/ob mice. Diabetes, 63, 1560-1571 (2014).

40) Yavari A, Stocker CJ, Ghaffari S, Wargent ET, Steeples V, Czibik G, Pinter K, Bellahcene M, Woods A, Martinez de Morentin PB, Cansell C, Lam BY, Chuster A, Petkevicius K, Nguyen-Tu MS, Martinez-Sanchez A, Pullen TJ, Oliver PL, Stockenhuber A, Nguyen C, Lazdam M, O'Dowd JF, Harikumar P, Toth M, Beall C, Kyriakou T, Parnis J, Sarma D, Katritsis G, Wortmann DD, Harper AR, Brown LA, Willows R, Gandra S, Poncio V, de Oliveira Figueiredo MJ, Qi NR, Peirson SN, McCrimmon RJ, Gereben B, Tretter L, Fekete C, Redwood C, Yeo GS, Heisler LK, Rutter GA, Smith MA, Withers DJ, Carling D, Sternick EB, Arch JR, Cawthorne MA, Watkins $\mathrm{H}$, Ashrafian $\mathrm{H}$. Chronic activation of $\gamma 2$ AMPK induces obesity and reduces $\beta$ cell function. Cell Metab., 23, 821-836 (2016)

41) Munday MR. Regulation of mammalian acetyl-CoA carboxylase. Biochem. Soc. Trans., 30, 1059-1064 (2002).

42) Sujobert P, Poulain L, Paubelle E, Zylbersztejn F, Grenier A, Lambert M, Townsend EC, Brusq JM, Nicodeme E, Decrooqc J, Nepstad I, Green AS, Mondesir J, Hospital MA, Jacque N, Christodoulou A, Desouza TA, Hermine O, Foretz M, Viollet B, Lacombe C, Mayeux P, Weinstock DM, Moura IC, Bouscary D, Tamburini J. Co-activation of AMPK and mTORC1 induces cytotoxicity in acute myeloid leukemia. Cell Reports, 11, 1446-1457 (2015).

43) Lee MS, Kim KJ, Kim D, Lee KE, Hwang JK. meso-Dihydroguaiaretic acid inhibits hepatic lipid accumulation by activating AMPactivated protein kinase in human HepG2 cells. Biol. Pharm. Bull., 34, 1628-1630 (2011).

44) O’Neill HM, Lally JS, Galic S, Thomas M, Azizi PD, Fullerton MD, Smith BK, Pulinilkunnil T, Chen Z, Samaan MC, Jorgensen SB, Dyck JR, Holloway GP, Hawke TJ, van Denderen BJ, Kemp $\mathrm{BE}$, Steinberg GR. AMPK phosphorylation of ACC2 is required for skeletal muscle fatty acid oxidation and insulin sensitivity in mice. Diabetologia, 57, 1693-1702 (2014).

45) Hardie DG, Pan DA. Regulation of fatty acid synthesis and oxidation by the AMP-activated protein kinase. Biochem. Soc. Trans., $\mathbf{3 0}$, 1064-1070 (2002).

46) Wei J, Zhang Y, Yu TY, Sadre-Bazzaz K, Rudolph MJ, Amodeo GA, Symington LS, Walz T, Tong L. A unified molecular mechanism for the regulation of acetyl-CoA carboxylase by phosphoryla- tion. Cell Discovery, 2, 16044 (2016).

47) Hwang YP, Kim HG, Choi JH, Do MT, Chung YC, Jeong TC, Jeong HG. S-Allyl cysteine attenuates free fatty acid-induced lipogenesis in human HepG2 cells through activation of the AMP-activated protein kinase-dependent pathway. J. Nutr. Biochem., 24, 1469-1478 (2013).

48) Witters LA, Gao G, Kemp BE, Quistorff B. Hepatic 5'-AMPactivated protein kinase: zonal distribution and relationship to acetyl-CoA carboxylase activity in varying nutritional states. Arch. Biochem. Biophys., 308, 413-419 (1994).

49) Wang Y, Viscarra J, Kim SJ, Sul HS. Transcriptional regulation of hepatic lipogenesis. Nat. Rev. Mol. Cell Biol., 16, 678-689 (2015).

50) Wang XH, Tian Y, Guo ZJ, Fan ZP, Qiu DK, Zeng MD. Cholesterol metabolism and expression of its relevant genes in cultured steatotic hepatocytes. J. Dig. Dis., 10, 310-314 (2009).

51) Yan F, Wang Q, Lu M, Chen W, Song Y, Jing F, Guan Y, Wang L, Lin Y, Bo T, Zhang J, Wang T, Xin W, Yu C, Guan Q, Zhou X, Gao L, Xu C, Zhao J. Thyrotropin increases hepatic triglyceride content through upregulation of SREBP-1c activity. J. Hepatol., 61, 1358-1364 (2014)

52) Kotzka J, Lehr S, Roth G, Avci H, Knebel B, Muller-Wieland D. Insulin-activated Erk-mitogen-activated protein kinases phosphorylate sterol regulatory element-binding protein-2 at serine residues 432 and 455 in vivo. J. Biol. Chem., 279, 22404-22411 (2004).

53) Sundqvist A, Bengoechea-Alonso MT, Ye X, Lukiyanchuk V, Jin J, Harper JW, Ericsson J. Control of lipid metabolism by phosphorylation-dependent degradation of the SREBP family of transcription factors by SCF(Fbw7). Cell Metab., 1, 379-391 (2005).

54) Bengoechea-Alonso MT, Punga T, Ericsson J. Hyperphosphorylation regulates the activity of SREBP1 during mitosis. Proc. Natl. Acad. Sci. U.S.A., 102, 11681-11686 (2005).

55) Punga T, Bengoechea-Alonso MT, Ericsson J. Phosphorylation and ubiquitination of the transcription factor sterol regulatory elementbinding protein-1 in response to DNA binding. J. Biol. Chem., 281, 25278-25286 (2006).

56) Li Y, Xu S, Mihaylova MM, Zheng B, Hou X, Jiang B, Park O, Luo Z, Lefai E, Shyy JY, Gao B, Wierzbicki M, Verbeuren TJ, Shaw RJ, Cohen RA, Zang M. AMPK phosphorylates and inhibits SREBP activity to attenuate hepatic steatosis and atherosclerosis in dietinduced insulin-resistant mice. Cell Metab., 13, 376-388 (2011).

57) Davie E, Forte GM, Petersen J. Nitrogen regulates AMPK to control TORC1 signaling. Curr. Biol., 25, 445-454 (2015).

58) Jo HK, Kim GW, Jeong KJ, Kim DY, Chung SH. Eugenol ameliorates hepatic steatosis and fibrosis by down-regulating SREBP1 gene expression via AMPK-mTOR-p70S6K signaling pathway. Biol. Pharm. Bull., 37, 1341-1351 (2014).

59) Porstmann T, Santos CR, Griffiths B, Cully M, Wu M, Leevers S, Griffiths JR, Chung YL, Schulze A. SREBP activity is regulated by mTORC1 and contributes to Akt-dependent cell growth. Cell Metab., 8, 224-236 (2008).

60) Hagiwara A, Cornu M, Cybulski N, Polak P, Betz C, Trapani F, Terracciano L, Heim MH, Ruegg MA, Hall MN. Hepatic mTORC2 activates glycolysis and lipogenesis through Akt, glucokinase, and SREBP1c. Cell Metab., 15, 725-738 (2012).

61) Yin Y, Gao L, Lin H, Wu Y, Han X, Zhu Y, Li J. Luteolin improves non-alcoholic fatty liver disease in $\mathrm{db} / \mathrm{db}$ mice by inhibition of liver $\mathrm{X}$ receptor activation to down-regulate expression of sterol regulatory element binding protein 1c. Biochem. Biophys. Res. Commun., 482, 720-726 (2017).

62) Yang J, Craddock L, Hong S, Liu ZM. AMP-activated protein kinase suppresses LXR-dependent sterol regulatory element-binding protein-1c transcription in rat hepatoma McA-RH7777 cells. J. Cell. Biochem., 106, 414-426 (2009).

63) Wong TY, Lin SM, Leung LK. The flavone luteolin suppresses SREBP-2 expression and post-translational activation in hepatic cells. PLOS ONE, 10, e0135637 (2015). 
64) Yang J, Maika S, Craddock L, King JA, Liu ZM. Chronic activation of AMP-activated protein kinase-alpha1 in liver leads to decreased adiposity in mice. Biochem. Biophys. Res. Commun., 370, 248-253 (2008).

65) Knowles C, Liu ZM, Yang J. Compensatory increase in lipogenic gene expression in adipose tissue of transgenic mice expressing constitutively active AMP-activated protein kinase-alphal in liver. Biochem. Biophys. Res. Commun., 412, 249-252 (2011).

66) Tan YQ, Wong TY, Lin SM, Leung LK. Dietary flavones counteract phorbol 12-myristate 13-acetate-induced SREBP-2 processing in hepatic cells. Mol. Cell. Biochem., 424, 163-172 (2017).

67) Liu S, Jing F, Yu C, Gao L, Qin Y, Zhao J. AICAR-induced activation of AMPK inhibits TSH/SREBP-2/HMGCR pathway in liver. PLOS ONE, 10, e0124951 (2015).

68) Lewin TM, Granger DA, Kim JH, Coleman RA. Regulation of mitochondrial $s n$-glycerol-3-phosphate acyltransferase activity: response to feeding status is unique in various rat tissues and is discordant with protein expression. Arch. Biochem. Biophys., 396, 119-127 (2001).

69) Lindén D, William-Olsson L, Rhedin M, Asztely AK, Clapham JC, Schreyer S. Overexpression of mitochondrial GPAT in rat hepatocytes leads to decreased fatty acid oxidation and increased glycerolipid biosynthesis. J. Lipid Res., 45, 1279-1288 (2004).

70) Muoio DM, Seefeld K, Witters LA, Coleman RA. AMP-activated kinase reciprocally regulates triacylglycerol synthesis and fatty acid oxidation in liver and muscle: evidence that $s n$-glycerol-3-phosphate acyltransferase is a novel target. Biochem. J., 338, 783-791 (1999).

71) Ruderman NB, Park H, Kaushik VK, Dean D, Constant S, Prentki M, Saha AK. AMPK as a metabolic switch in rat muscle, liver and adipose tissue after exercise. Acta Physiol. Scand., 178, 435-442 (2003).

72) Park H, Kaushik VK, Constant S, Prentki M, Przybytkowski E, Ruderman NB, Saha AK. Coordinate regulation of malonyl-CoA decarboxylase, $s n$-glycerol-3-phosphate acyltransferase, and acetylCoA carboxylase by AMP-activated protein kinase in rat tissues in response to exercise. J. Biol. Chem., 277, 32571-32577 (2002).
73) Yuan HD, Piao GC. An active part of Artemisia sacrorum Ledeb. inhibits adipogenesis via the AMPK signaling pathway in 3T3-L1 adipocytes. Int. J. Mol. Med., 27, 531-536 (2011).

74) Anthony NM, Gaidhu MP, Ceddia RB. Regulation of visceral and subcutaneous adipocyte lipolysis by acute AICAR-induced AMPK activation. Obesity, 17, 1312-1317 (2009).

75) Yeaman SJ. Hormone-sensitive lipase-New roles for an old enzyme. Biochem. J., 379, 11-22 (2004).

76) Daval M, Diot-Dupuy F, Bazin R, Hainault I, Viollet B, Vaulont S, Hajduch E, Ferre P, Foufelle F. Anti-lipolytic action of AMPactivated protein kinase in rodent adipocytes. J. Biol. Chem., 280, 25250-25257 (2005).

77) Yin W, Mu J, Birnbaum MJ. Role of AMP-activated protein kinase in cyclic AMP-dependent lipolysis in 3T3-L1 adipocytes. J. Biol. Chem., 278, 43074-43080 (2003).

78) Ahmadian M, Abbott MJ, Tang T, Hudak CS, Kim Y, Bruss M, Hellerstein MK, Lee HY, Samuel VT, Shulman GI, Wang Y, Duncan RE, Kang C, Sul HS. Desnutrin/ATGL is regulated by AMPK and is required for a brown adipose phenotype. Cell Metab., 13, 739-748 (2011).

79) Kim SJ, Tang T, Abbott M, Viscarra JA, Wang Y, Sul HS. AMPK phosphorylates desnutrin/ATGL and hormone-sensitive lipase to regulate lipolysis and fatty acid oxidation within adipose tissue. Mol. Cell. Biol., 36, 1961-1976 (2016).

80) Roepstorff C, Vistisen B, Donsmark M, Nielsen JN, Galbo H, Green KA, Hardie DG, Wojtaszewski JF, Richter EA, Kiens B. Regulation of hormone-sensitive lipase activity and Ser563 and Ser565 phosphorylation in human skeletal muscle during exercise. J. Physiol., 560, 551-562 (2004).

81) Watt MJ, Steinberg GR, Chan S, Garnham A, Kemp BE, Febbraio MA. $\beta$-Adrenergic stimulation of skeletal muscle HSL can be overridden by AMPK signaling. FASEB J., 18, 1445-1446 (2004).

82) Zhang X, Song Y, Feng M, Zhou X, Lu Y, Gao L, Yu C, Jiang X, Zhao J. Thyroid-stimulating hormone decreases HMG-CoA reductase phosphorylation via AMP-activated protein kinase in the liver. J. Lipid Res., 56, 963-971 (2015). 